(2) Open Access Full Text Article

\title{
Reversible global aphasia as a side effect of quetiapine: a case report and literature review
}

This article was published in the following Dove Press journal:

Neuropsychiatric Disease and Treatment

28 August 2017

Number of times this article has been viewed

\author{
Ching-Fang Chien' \\ Poyin Huang ${ }^{1,2}$ \\ Sun-Wung Hsieh ${ }^{1,2}$ \\ 'Department of Neurology, \\ Kaohsiung Medical University \\ Hospital, Kaohsiung, Taiwan: \\ ${ }^{2}$ Department of Neurology, \\ Kaohsiung Municipal Hsiao-Kang \\ Hospital, Kaohsiung, Taiwan
}

\begin{abstract}
Quetiapine is an atypical antipsychotic agent which is also prescribed for delirium due to its anti-dopaminergic effects; aphasia is an unusual side effect associated with the drug. Here, we report the case of an 83-year-old woman who was prescribed quetiapine ( $50 \mathrm{mg}$ per day) for delirium. Unexpected, global aphasia occurred 3 days after treatment began. Complete recovery occurred following discontinuation of the drug. A brain computed tomography scan excluded intracranial hemorrhage and the laboratory results confirmed that no exacerbation of infection or electrolyte imbalances were present. During the aphasic episode, the patient's condition did not deteriorate and no new neurological symptoms occurred. We suspect that the occurrence of aphasia was directly due to an adverse reaction to quetiapine. To our knowledge, this is the first case report of reversible, global aphasia as a side effect of quetiapine. We propose that this occurrence of aphasia may be due to the action of quetiapine as a dopamine receptor antagonist. Clinicians should use quetiapine with caution, especially in elderly patients. On observation of aphasia, a review of the patient's medical history is required to assess for the usage of quetiapine.
\end{abstract}

Keywords: aphasia, quetiapine, insomnia, delirium

\section{Introduction}

Quetiapine is a new, atypical antipsychotic medication, and its usage has become more frequent due to its excellent disease control and the presence of fewer extrapyramidal side effects compared to other atypical antipsychotics. It is predominantly used for the treatment of schizophrenia and bipolar disorder. It is also used to treat delirium due to its anti-dopaminergic effects. Although it is generally well-tolerated, several adverse reactions have been associated with the usage of Quetiapine, especially in elderly patients. ${ }^{1}$ These include ischemic stroke, orthostatic hypotension, seizure, drowsiness, Stevens-Johnson syndrome, and suicidal ideation. Aphasia is rare side effect associated with quetiapine. Here, we present a case of global aphasia as a side effect of quetiapine usage. We go on to discuss the possible mechanisms behind this adverse reaction.

\section{Case history}

An 83-year-old, right handed, Chinese female patient presented at our clinic with a medical history of diabetes, hypertension, and an old ischemic stroke in the left cerebral hemisphere (corona radiata and lentiform nucleus) with sequelae of right mild hemiparesis. On presentation, no aphasia was observed. According to her medical history, the patient had been prescribed with low dose Risperdal ${ }^{\circledR}$ (risperidone; Johnson \& Johnson, New Brunswick, NJ, USA) (0.5 mg per night) for the past 3 months. She was
Correspondence: Sun-Wung Hsieh Kaohsiung Municipal Hsiao-Kang Hospital 482 Shanming Rd, Siaogang District, Kaohsiung City 812, Taiwan

Tel 886-7803-6783-3402

Fax 886-7806-5068

Email circle.6@yahoo.com.tw 
conscious, alert and spoke fluently. The patient was partially dependent due to right hemiparesis. She was admitted to the infection ward via the emergency department with suspected urinary tract infection, hyperglycemia, and hyponatremia. During hospitalization, the infection and hyponatremia were treated and controlled; however, the patient still maintained mild delirium as well as insomnia. On the 7th day of hospitalization, to treat the delirium, the clinician prescribed extended-release quetiapine at $50 \mathrm{mg}$ per day in replacement of risperidone. Following the administration of quetiapine, the patient presented with acute global aphasia and an inability to follow instructions. Upon neurological examination, no new symptoms or signs were detected. The patient's systolic blood pressure was around 120-160 $\mathrm{mmHg}$ during hospitalization. Complete laboratory studies, including complete blood count and biochemistry profiles, confirmed that no further exacerbations of infection, electrolyte imbalances or other metabolic problems were present. Emergent brain computed tomography indicated that there was no intracranial hemorrhage. On the 7 th day of hospitalization we prescribed quetiapine, but the unexpected aphasia persisted for 3 days, so we then ceased quetiapine on the the 10th day of hospitalization. We suggested the need for further brain imaging to exclude a new cerebral ischemic infarction or seizure disorder; however, the patient asked to be discharged before we could undertake these studies. In the outpatient follow-up, 1 week after discharge, no recurrent aphasic episodes had occurred. Despite the lack of a complete brain survey, we strongly suspected that the unexpected, reversible, global aphasia was a direct adverse reaction to quetiapine.

Written informed consent has been provided by the patient to have the case details published.

\section{Discussion}

Here, we describe an 83-year-old, delirious female who presented with acute global aphasia following quetiapine administration, which completely recovered following discontinuation of the drug. To the best of our knowledge, this is the first case report of reversible global aphasia as a side effect of quetiapine.

The atypical antipsychotic drug quetiapine is a dibenzothiazepine derivative, with a similar chemical structure to clozapine. It shares characteristics with dopaminergic (D1, D2, D3, D4 receptor) antagonists, adrenergic ( $\alpha 1, \alpha 2$ receptor) antagonists, 5-HT1A partial agonists, high affinity 5-HT2A partial antagonists, and potentially shares properties with histamine (H1 receptor) antagonists. ${ }^{2-4}$ The main indications for quetiapine are schizophrenia, bipolar disorder, and delirium.

A lesion blocking the language network can result in aphasia, hence the most common etiology of aphasia is a vascular event. ${ }^{5}$ As the patient had a previous history of ischemic stroke, the probability of recurrent stroke and transient ischemic attack (TIA) increased. In this patient, no further deterioration or new neurological symptoms and signs occurred during the aphasic episode and the aphasia fully recovered following the discontinuation of quetiapine. TIA typically presents with new neurological signs that resolve within 24 hours. In our patient, aphasia persisted for 3 days, which is not compatible with the definition of TIA. Upon brain magnetic resonance imaging, no new lesions were observed. We concluded that in this patient TIA or a recurrent stroke involving language function was unlikely to have occurred. Although one of the side effects of quetiapine is orthostatic hypotension, which may cause ischemic stroke, the patient's blood pressure remained in the normal to mildly hypertensive range during hospitalization.

Aphasia can also result from degenerative diseases, seizure disorders, or medication usage. The course of degenerative disease is often slowly progressive and irreversible. Our case was not compatible with the clinical presentation of degenerative disease. Both the ictal and post-ictal phases of a seizure can manifest with aphasia. ${ }^{6-7}$ During hospitalization, we did not witness any limb convulsions or focal tremor in the patient. Therefore, a seizure disorder diagnosis was not favored.

So far, several medications have been reported to cause aphasia, including: ipilimumab; immunomodulatory drugs (thalidomide, lenalidomide, pomalidomide); lamotrigine; vigabatrin; sulfasalazine; cyclosporine A; ifosfamide; phenylpropanolamine; naftidrofuryl oxalate; and some contrast mediums (Table 1). In the reported cases of medicationassociated aphasia, aphasia completely recovered following discontinuation of the medication. Medication induced central neurotoxicity can lead to aphasia. However, other mechanisms leading to aphasia are unclear. Previous studies have concluded that increased dopamine levels can improve speech function in transcortical motor aphasia. The improvements in speech function gradually disappeared when dopamine levels decreased. ${ }^{8,9}$ Acetylcholine is known to be involved in the verbal memory process and can have benefits in the treatment of aphasia. The influence of amphetamine and serotonin on language is still controversial. Risperidone has a stronger affinity for dopaminergic receptors than quetiapine. It is reasonable to hypothesize that risperidone usage would result in similar symptoms in this patient. The patient had a history of taking low dose, short-acting risperidone (before sleep), which achieved peak plasma levels within 1 hour and had a half-life of 3 hours. We removed risperidone from the patient's regime and instead prescribed extended-released 
Table I Reported medication causing aphasia in literature review

\begin{tabular}{|c|c|c|c|}
\hline Drug & Symptoms & Mechanism & $\begin{array}{l}\text { Level of } \\
\text { evidence }\end{array}$ \\
\hline Ipilimumab ${ }^{10}$ & $\begin{array}{l}\text { Aphasia, tremor and ataxia, myocloni, hallucinations, } \\
\text { anxiety and agitation in turns with somnolence }\end{array}$ & $\begin{array}{l}\text { Unclear, suspect related to anti-thyroid } \\
\text { antibodies }\end{array}$ & Case report \\
\hline $\begin{array}{l}\text { Immunomodulatory drugs }{ }^{\prime \prime} \\
\text { (thalidomide, lenalidomide, } \\
\text { pomalidomide) }\end{array}$ & $\begin{array}{l}\text { Reversible coma, amnesia, expressive aphasia, and } \\
\text { dysarthria }\end{array}$ & Central neurotoxicity & Case series \\
\hline Lamotrigine $^{12}$ & Global aphasia & EEG showed continuous spikes and waves & Case report \\
\hline Vigabatrin ${ }^{13}$ & Aphasia disorder & Unclear & Case report \\
\hline Sulfasalazine ${ }^{14}$ & Dysphasia, seizures, rash & Unclear & Case report \\
\hline Cyclosporine $A^{15}$ & Aphasia & Central neurotoxicity & Case report \\
\hline Ifosfamide ${ }^{16}$ & Confusion, aphasia, hallucinations, and coma & Central neurotoxicity & Case series \\
\hline Phenylpropanolamine ${ }^{17}$ & Acute memory loss and nominal aphasia & Unclear & Case report \\
\hline $\begin{array}{l}\text { Contrast (cardiac } \\
\text { catheterization) })^{18}\end{array}$ & $\begin{array}{l}\text { Encephalopathy, motor and sensory disturbances, vision } \\
\text { disturbance, ophthalmoplegia, aphasia, and seizures }\end{array}$ & $\begin{array}{l}\text { I. Disruption of the BBB and direct neuronal } \\
\text { injury; } 2 \text {. Transient vasoconstriction }\end{array}$ & Case series \\
\hline Metrizamide myelography ${ }^{19}$ & Expressive dysphasia & Neurotoxic reaction & Case series \\
\hline Naftidrofuryl oxalate $e^{20}$ & Aphasia & Unclear & Case report \\
\hline Cisplatin ${ }^{21}$ & Aphasia, confusion, and agitation & Central neurotoxicity & Case report \\
\hline
\end{tabular}

Abbreviations: EEG, electroencephalography; BBB, blood-brain barrier.

quetiapine. Quetiapine usage resulted in prominent aphasia. We proposed that quetiapine may result in aphasia through its anti-dopaminergic activity. We also suspected that old age and the presence of a previous ischemic stroke (which interfered with the adjacent nigrostriatal pathway) contributed to the development of aphasia in this case.

\section{Conclusion}

We reasoned that aphasia occurred as a rare adverse reaction of quetiapine, through its anti-dopaminergic activity. When treating delirium, clinicians should use quetiapine with caution, especially in elderly patients. On observation of aphasia, the medical history should be reviewed and quetiapine induced side effects should be kept in mind. These side effects may be reversible following the discontinuation of quetiapine.

\section{Disclosure}

The authors report no conflicts of interest in this work.

\section{References}

1. El-Saifi N, Jones C, Moyle W. Quetiapine adverse events in older adults in Australia. Australas J Ageing. 2016;35(4):281-284.

2. Gefvert O, Lundberg T, Wieselgren IM, et al. D(2) and 5HT(2A) receptor occupancy of different doses of quetiapine in schizophrenia: a PET study. Eur Neuropsychopharmacol. 2001;11:105-110.

3. Richelson E, Souder T. Binding of antipsychotic drugs to human brain receptors focus on newer generation compounds. Life Sci. 2000;68:29-39.

4. Sato H, Ito C, Hiraoka K, et al. H1 receptor occupancy by the newgeneration antipsychotics olanzapine and quetiapine: a positron emission tomography study in healthy volunteers. Psychopharmacology (Berl). 2015;232:3497-3505.

5. Goodglass H. Understanding Aphasia. San Diego: Academic Press; 1993.
6. Aladdin Y, Snyder TJ, Ahmed SN. Pearls \& Oy-sters: selective postictal aphasia: cerebral language organization in bilingual patients. Neurology. 2008;71:e14.

7. Profitlich T, Hoppe C, Reuber M, et al. Ictal neuropsychological findings in focal nonconvulsive status epilepticus. Epilepsy Behav. 2008; 12(2):269-275.

8. Klein RB, Albert ML. Can drug therapies improve language functions of individuals with aphasia? A review of the evidence. Semin Speech Lang. 2004;25(2):193-204.

9. Gill SK, Leff AP. Dopaminergic therapy in aphasia. Aphasiology. 2012; 28:155-170.

10. Carl D, Grüllich C, Hering S, et al. Responsive encephalopathy associated with autoimmune thyroiditis following ipilimumab therapy: a case report. BMC Res Notes. 2015;8:316.

11. Patel UH, Mir MA, Sivik JK, Raheja D, Pandey MK, Talamo G. Central neurotoxicity of immunomodulatory drugs in multiple myeloma. Hematol Rep. 2015;7(1):5704.

12. Battaglia D, Iuvone L, Stefanini MC, et al. Reversible aphasic disorder induced by lamotrigine in atypical benign childhood epilepsy. Epileptic Disord. 2001;3:217-222.

13. Gil R, Neau JP. Rapid aggravation of aphasia by vigabatrin. J Neurol. 1995;242:251-252.

14. Hill ME, Gordon C, Situnayake RD, Heath DA. Sulfasalazine induced seizures and dysphasia. J Rheumatol. 1994;21:748-749.

15. RodríguezE, Delucchi A,CanoF. Neurotoxicidad por ciclosporina A en trasplante renal en niños [Neurotoxicity caused by cyclosporin A in renal transplantation in children]. Rev Med Chil. 1992;120:300-303. Spanish.

16. Curtin JP, Koonings PP, Gutierrez M, Schlaerth JB, Morrow CP. Ifosfamide-induced neurotoxicity. Gynecol Oncol. 1991;42:193-196.

17. Puar HS. Acute memory loss and nominal aphasia caused by phenylpropanolamine. South Med J. 1984;77:1604-1605.

18. Spina R, Simon N, Markus R, Muller DWM, Kathir K. Contrast-induced encephalopathy following cardiac catheterization. Catheter Cardiovasc Interv. 2016;90(2):257-268.

19. Sarno JB. Transient expressive (nonfluent) dysphasia after metrizamide myelography. AJNR Am J Neuroradiol. 1985;6(6):945-947.

20. Matschke RG. Allergische Reaktion bei Therapie mit Naftidrofuryl (Dusodril). Ein Fallbericht [Allergic reaction in therapy with naftidrofuryl (Dusodril). A case report]. HNO. 1987;35:219-221. German.

21. Higa GM, Wise TC, Crowell EB. Severe, disabling neurologic toxicity following cisplatin retreatment. Ann Pharmacother. 1995;29(2): $134-137$. 


\section{Publish your work in this journal}

Neuropsychiatric Disease and Treatment is an international, peerreviewed journal of clinical therapeutics and pharmacology focusing on concise rapid reporting of clinical or pre-clinical studies on a range of neuropsychiatric and neurological disorders. This journal is indexed on PubMed Central, the 'PsycINFO' database and CAS, and is the official journal of The International Neuropsychiatric Association (INA). The manuscript management system is completely online and includes a very quick and fair peer-review system, which is all easy to use. Visit http://www.dovepress.com/testimonials.php to read real quotes from published authors.

\footnotetext{
Submit your manuscript here: http://www.dovepress.com/neuropsychiatric-disease-and-treatment-journal
} 